\title{
NEOPLASIA BLÁSTICA DE CÉLULAS DENDRÍTICAS PLASMOCITOIDES VARIANTE LEUCEMIA AGUDA: REPORTE DE UN CASO
}

\author{
Carlos Flores-Angulo 1,2,a,b , Zulay Chona 1,b, María A Sánchez ${ }^{1, b}$, Mauricio Salazar 1,b, Helen Hennig 1,b
}

\begin{abstract}
RESUMEN
La neoplasia blástica de células dendríticas plasmocitoides (NBCDP) es una malignidad hematológica poco frecuente y generalmente agresiva, por lo cual se requiere su reconocimiento precoz. A continuación, se describe el curso clínico prolongado de un paciente masculino de 60 años con NBCDP procedente de Venezuela, en cuyos hallazgos más relevantes destacó la presencia de lesiones cutáneas, organomegalias, infiltración de la médula ósea y del sistema nervioso central. Posterior al diagnóstico se indicó quimioterapia sistémica, no obstante, el paciente falleció por complicaciones respiratorias durante la fase de inducción del tratamiento. En esta enfermedad es necesario establecer el diagnóstico diferencial con trastornos linfoproliferativos, leucemias linfoides y mieloides agudas, constituyendo el análisis morfológico de las células neoplásicas un aspecto importante para una adecuada orientación diagnóstica.
\end{abstract}

Palabras clave: Neoplasia blástica de células dendríticas plasmocitoides; malignidad hematológica; Leucemia Mieloide Aguda (fuente: DeCS BIREME).

\section{BLASTIC PLASMACYTOID DENDRITIC CELL NEOPLASM VARIANT ACUTE LEUKEMIA: CASE REPORT}

\begin{abstract}
Blastic plasmacytoid dendritic cell blast neoplasm (BPDCN) is a rare and generally aggressive hematologic malignancy, requiring early recognition. Below is a description of the prolonged clinical course of a 60-year-old male patient with BPDCN from Venezuela, whose most relevant findings highlighted the presence of skin lesions, organomegaly, infiltration of the bone marrow and central nervous system. Systemic chemotherapy was prescribed after diagnosis; however, the patient died of respiratory complications during the induction phase of treatment. In this disease, it is necessary to establish the differential diagnosis with lymphoproliferative disorders, acute lymphoid and myeloid leukemias. The morphological analysis of neoplastic cells is, thus, an important aspect toward proper diagnostic guidance.
\end{abstract}

Keywords: Blastic plasmacytoid dendritic cell neoplasm, hematologic malignancy, acute myeloid leukemia (source: MeSH NLM).

\section{INTRODUCCIÓN}

La neoplasia blástica de células dendríticas plasmocitoides (NBCDP) es una enfermedad maligna cuyo precursor es la célula dendrítica plasmocitoide (CDp), se caracteriza por afectar a piel y ganglios linfáticos, pero puede evolucionar a una forma diseminada e infiltrar a la médula ósea ${ }^{(1)}$. Aunque había sido clasificada en el grupo de leucemias mieloides agudas (LMA), en el 2016 la OMS la catalogó como una entidad independiente.

La etiología sigue siendo desconocida, pero existen alteraciones asociadas a la enfermedad, siendo el cariotipo complejo, la afectación de 12p13 y los rearreglos de MYC las más comunes ${ }^{(2)}$. Los estudios moleculares han demostrado una mayor expresión de $B C L 2, T C L 1 A / B$ y $M Y C$ en la NBCDP, teniendo participación el factor de transcripción TCF4 ${ }^{(3)}$. Otras alteraciones incluyen: -5 , del( $(5 q),-7$, del $(7 q)$, del(9q), del(11q) y del(13q), inactivación de supresores de tumores (RB1, TP53, CDKN2A), activación de oncogenes (NRAS, KRAS) y mutaciones en regulares epigenéticos (TET2, TET1, DNMT3A, IHD2) (2).

Por la baja incidencia, aproximadamente $0,44 \%$ de todas las malignidades hematológicas, y su agresividad ${ }^{(1,4)}$, a continuación, se describe el curso clínico poco habitual de un adulto con NBCDP variante leucemia aguda.

\footnotetext{
Servicio de Hematología y Banco de Sangre, Hospital Universitario de Caracas (HUC). Caracas, Venezuela.

Sección de Polimorfismos Genómicos, Instituto de Investigaciones Biomédicas “Dr. Francisco J. Triana Alonso", Universidad de Carabobo, Maracay, Venezuela.

Magíster en Ciencias Biomédicas; ${ }^{\mathrm{b}}$ Médico hematólogo.

Recibido: 30/06/2018 Aprobado: 08/05/2019 En línea: 28/06/2019
}

Citar como: Flores-Angulo C, Chona Z, Sánchez MA, Salazar M, Hennig H. Neoplasia blástica de células dendríticas plasmocitoides variante leucemia aguda: reporte de un caso. Rev Peru Med Exp Salud Publica. 2019;36(2):353-9. doi: http://dx.doi.org/10.17843/rpmesp.2019.362.3779. 


\section{REPORTE DE CASO}

Paciente masculino de 60 años, natural de Caracas Venezuela, que inició enfermedad en mayo de 2015 cuando presentó tumor hipercrómico en cara anterior del antebrazo izquierdo (10 $\mathrm{mm}$ de diámetro) sin otro concomitante. En el transcurso de 6 meses, se evidenció aumento de tamaño $(3,0 \times 5,5 \mathrm{~cm})$, por ello acudió a consulta de dermatología donde se realizó biopsia cutánea, cuyo análisis reportó densa proliferación de células linfoides en la dermis con infiltración al tejido subcutáneo, las células presentaron núcleos redondeados, aclaramiento de la paracromatina, reforzamiento del borde nuclear y nucléolo pequeño, aunque el infiltrado respeta la epidermis esta se encontró adelgazada y aplanada, el conjunto de hallazgos fueron compatibles con linfoma cutáneo. Dicha muestra fue reevaluada por dermatopatólogo que reportó el mismo diagnóstico e indicó estudio inmunohistoquímico; sin embargo, el paciente decidió no realizarlo.

La enfermedad evolucionó durante 29 meses y la lesión cutánea primaria aumentó progresivamente de tamaño, además, se documentó la aparición de otras lesiones similares a la primera en el resto de la piel. Por tales motivos, acudió a médico oncólogo que ante los hallazgos histológicos refirió al Hospital Universitario de Caracas (HUC).

En el examen físico se documentaron múltiples nódulos y tumores hipercrómicos (Figura 1A), la de mayor tamaño $(10 \times 10 \mathrm{~cm})$, circular, con bordes elevados, fondo necrótico y signos de flogosis positivos, se encontró localizada en la cara anterior del antebrazo (Figura 1B); a la palpación se documentó esplenomegalia (Boyd II), resto anodino.

En el hemograma se evidenció leucocitos $6,2 \times 10 \%$ (neutrófilos $61 \%$, linfocitos 30\% y eosinófilos $9 \%$ ), Hb 12,9 $\mathrm{g} / \mathrm{dL}$ y plaquetas $198 \times 10 \%$, la química sanguínea (glucemia, urea, creatinina, ácido úrico, electrolitos, LDH y transaminasas) se encontró en límites normales, VDRL negativo y VIH-1/2 no reactivo. En la TAC de tórax, abdomen y pelvis con doble contraste se evidenció esplenomegalia y adenopatías (>10 mm) en región axilar izquierda y retroperitoneo. El paciente no presentó síntomas de afectación neurológica.

Se realizó frotis de sangre periférica donde se evidenció $60 \%$ de células de aspecto inmaduro (Figura 2A). En el estudio del extendido de médula ósea se observaron células de mediano/gran tamaño, aumento de la relación núcleo:citoplasma, eucromatina, presencia de nucléolos y prolongaciones citoplasmáticas (Figura 2B, C y D).

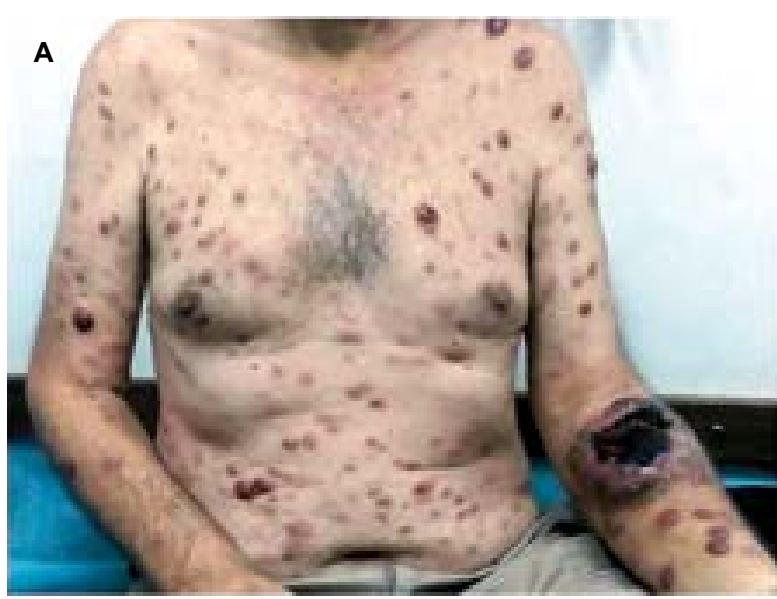

B

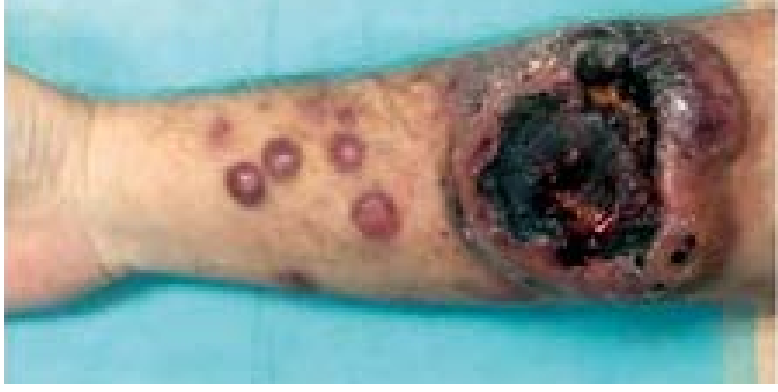

A) Presencia de gran número nódulos y tumores en la piel del paciente; B) Lesión primaria ubicada en la cara anterior del antebrazo izquierdo de aproximadamente $10 \mathrm{~cm}$ de diámetro, con bordes elevados y fondo necrótico, se documentó la presencia de signos de flogosis.

Figura 1. Características de lesiones cutáneas de paciente con diagnóstico de neoplasia blástica de células dendríticas plasmocitoides

Se analizó una muestra de médula ósea mediante citometría de flujo, donde se documentó el inmunofenotipo CD2+/CD7-/CD3-/CD4+débil/CD56+/CD123+/HLADR+ en el $70 \%$ de la población celular (Figura 3). Además, se realizó estudio del líquido cefalorraquídeo donde se evidenciaron 49 células ( $100 \%$ mononucleares) sin presencia de hematíes, compatible con infiltración leptomeníngea.

Por tales motivos, se realizó el diagnóstico de NBCDP variante leucemia aguda riesgo intermedio y se indicó un esquema de tratamiento para leucemia linfoblástica aguda (LLA) inspirado en un protocolo pediátrico descrito por el International BFM Study Group (BFM-95) (Tabla 1) ${ }^{(5)}$.

A los cuatro días de la fase de inducción, el paciente presentó tos productiva y disnea; por ello, acudió al servicio de emergencia donde fue evaluado e ingresado para establecer el diagnóstico. No obstante, se describió un rápido deterioro clínico, declarándose su muerte a las dos horas del ingreso. 


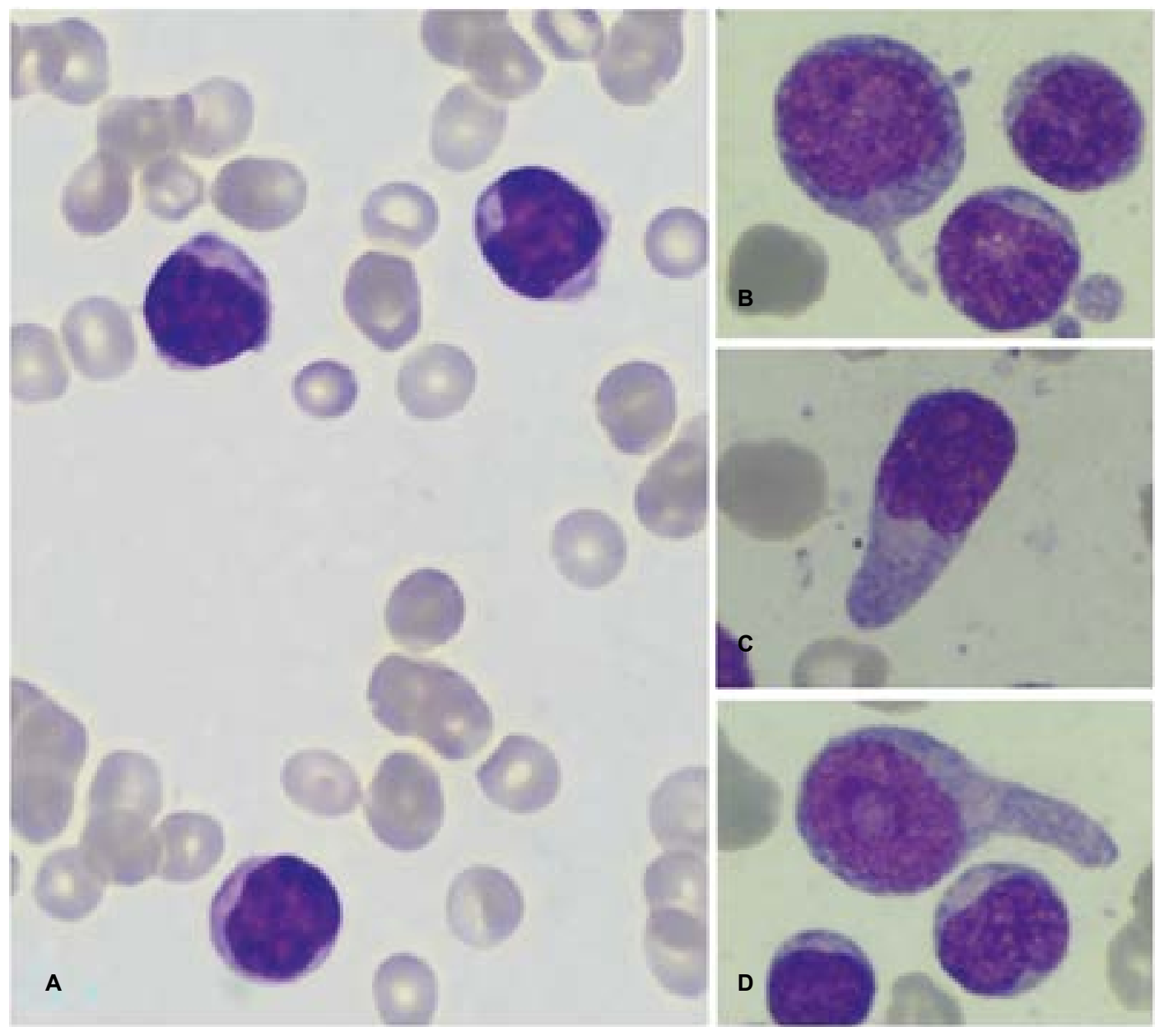

A) Extendido de sangre periférica (Wright-Giemsa; 1000x), se observó la presencia de una población uniforme de células mononucleares de mediano a gran tamaño, con aumento en la relación núcleo:citoplasma $(\mathrm{N}: \mathrm{C})$, destacó la presencia de eucromatina con algunos agregados perinucleares de heterocromatina, en algunas células se evidenciaron gránulos citoplasmáticos; $\mathrm{B}, \mathrm{C}$ y D) Extendido de médula ósea (Wright-Giemsa; 1000x), destacó la presencia de células de mediano a gran tamaño, aumento de la relación $\mathrm{N}: \mathrm{C}$, algunos núcleos con escotadura, eucromatina, presencia de nucléolos y prolongaciones citoplasmáticas, se evidenció escasa reserva medular residual.

Figura 2. Muestra de sangre periférica y médula ósea de paciente con diagnóstico de neoplasia blástica de células dendríticas plasmocitoides

\section{DISCUSIÓN}

La NBCDP es una enfermedad maligna poco común, diagnosticada con mayor frecuencia en adultos del sexo masculino. El cuadro clínico típico contempla la presencia de lesiones en piel, linfadenopatías y organomegalias ${ }^{(6-12)}$, siendo concordante a lo descrito en el presente reporte. Las lesiones cutáneas se caracterizan por ser variables en tamaño, forma y color, pueden presentarse como tumores, nódulos y placas afectando generalmente a cara, tronco y extremidades ${ }^{(1)}$.

Aunque la infiltración de la médula ósea es un hallazgo frecuente ${ }^{(6-11)}$, se ha observado a la variante leucémica sin otra manifestación ${ }^{(10)}$. Respecto a la afectación neurológica, aproximadamente el $30 \%$ de los pacientes tienen compromiso del sistema nervioso central (SNC) ${ }^{(6-12)}$, lo cual motivó la evaluación del líquido cefalorraquídeo (LCR); si bien, en el protocolo BFM-95 el estado del SNC no modifica el riesgo clínico, en presencia de infiltración leptomeníngea se requiere una intervención terapéutica adicional (Tabla 1).

Lo anterior, pone de manifiesto que se trata de una enfermedad muy heterogénea siendo necesario el diagnóstico diferencial con otros trastornos neoplásicos, ya que algunos pueden presentarse sólo con linfadenopatías y organomegalias ${ }^{(11,12)}$. Sin embargo, también es importante descartar ciertas infecciones que pueden presentar 


\begin{tabular}{|c|c|c|c|c|c|c|c|c|c|c|c|c|c|}
\hline $\begin{array}{l}\text { Muestra } \\
\text { Ref. }\end{array}$ & $\begin{array}{c}\text { MO } \\
\ddagger\end{array}$ & $\begin{array}{l}\text { Piel } \\
(6)^{*}\end{array}$ & $\begin{array}{l}\text { MO } \\
(6)^{*}\end{array}$ & $\begin{array}{l}\text { MO } \\
(7)\end{array}$ & $\begin{array}{l}\text { MO } \\
(8)^{*}\end{array}$ & $\begin{array}{l}\mathrm{GL} \\
(8)^{*}\end{array}$ & $\begin{array}{l}\text { GL } \\
\text { (9) }\end{array}$ & $\begin{array}{l}\text { MO } \\
(10)^{*}\end{array}$ & $\begin{array}{l}\text { GL } \\
(10)^{*}\end{array}$ & $\begin{array}{l}\text { SP } \\
(10)\end{array}$ & $\begin{array}{l}\text { MO } \\
\text { (11) }\end{array}$ & $\begin{array}{l}\text { MO } \\
\text { (11) }\end{array}$ & $\begin{array}{l}\text { Piel } \\
\text { (12) }\end{array}$ \\
\hline \multicolumn{14}{|l|}{ HLADR } \\
\hline \multicolumn{14}{|l|}{ TdT } \\
\hline \multicolumn{14}{|l|}{ MPO } \\
\hline \multicolumn{14}{|l|}{ AßTCR } \\
\hline \multicolumn{14}{|l|}{ ГঠTCR } \\
\hline \multicolumn{14}{|l|}{ PAX5 } \\
\hline \multicolumn{14}{|l|}{ EBER } \\
\hline \multicolumn{14}{|l|}{$\mathrm{BCL} 2$} \\
\hline \multicolumn{14}{|l|}{ Ciclina D } \\
\hline \multicolumn{14}{|l|}{ TCL-1 } \\
\hline \multicolumn{14}{|l|}{ CD1a } \\
\hline \multicolumn{14}{|l|}{ CD2 } \\
\hline \multicolumn{14}{|l|}{ CD3 } \\
\hline \multicolumn{14}{|l|}{ cytCD3 } \\
\hline \multicolumn{14}{|l|}{ CD4 } \\
\hline \multicolumn{14}{|l|}{ CD5 } \\
\hline \multicolumn{14}{|l|}{ CD7 } \\
\hline \multicolumn{14}{|l|}{ CD8 } \\
\hline CD10 & & & & & & & & & & & & & \\
\hline CD11b & & & & & & & & & & & & & \\
\hline CD11c & & & & & & & & & & & & & \\
\hline CD13 & & & & & & & & & & & & & \\
\hline CD14 & & & & & & & & & & & & & \\
\hline CD15 & & & & & & & & & & & & & \\
\hline CD16 & & & & & & & & & & & & & \\
\hline CD19 & & & & & & & & & & & & & \\
\hline CD20 & & & & & & & & & & & & & \\
\hline CD22 & & & & & & & & & & & & & \\
\hline CD25 & & & & & & & & & & & & & \\
\hline CD30 & & & & & & & & & & & & & \\
\hline CD33 & & & & & & & & & & & & & \\
\hline CD34 & & & & & & & & & & & & & \\
\hline CD38 & & & & & & & & & & & & & \\
\hline CD43 & & & & & & & & & & & & & \\
\hline CD45 & & & & & & & & & & & & & \\
\hline CD45RA & & & & & & & & & & & & & \\
\hline CD56 & & & & & & & & & & & & & \\
\hline CD57 & & & & & & & & & & & & & \\
\hline CD64 & & & & & & & & & & & & & \\
\hline CD68 & & & & & & & & & & & & & \\
\hline CD79a & & & & & & & & & & & & & \\
\hline CD94 & & & & & & & & & & & & & \\
\hline CD99 & & & & & & & & & & & & & \\
\hline CD117 & & & & & & & & & & & & & \\
\hline CD123 & & & & & & & & & & & & & \\
\hline CD138 & & & & & & & & & & & & & \\
\hline CD303 & & & & & & & & & & & & & \\
\hline CD304 & & & & & & & & & & & & & \\
\hline
\end{tabular}

Ref.: Referencia bibliográfica; ł: Presente caso; *: Análisis de dos muestras en un mismo paciente; Rojo: Positivo; Amarillo: Dim; Azul: Negativo; Blanco: No evaluado/No documentado; MO: Médula ósea; GL: Ganglio linfático; SP: Sangre periferica.

Figura 3. Características inmunofenotípicas de muestras biológicas analizadas en casos publicados de neoplasia blástica de células dendríticas plasmocitoides 
Tabla 1. Esquema de tratamiento empleado en el presente caso (Protocolo de leucemia linfoblástica aguda, modificado del BFM-95)

\begin{tabular}{|c|c|c|}
\hline Droga & Dosis & Días \\
\hline \multicolumn{3}{|l|}{ Inducción (Fase $A)^{\varepsilon}$} \\
\hline Prednisona (VO) & $60 \mathrm{mg} / \mathrm{m}^{2} / \mathrm{día}$ & $1-29$ \\
\hline Vincristina (IV) & $1,5 \mathrm{mg} / \mathrm{m}^{2} /$ dosis (Max. $2 \mathrm{mg}$ ) & $8,15,22,29$ \\
\hline Daunorrubiicina (IV) & $30 \mathrm{mg} / \mathrm{m}^{2} /$ dosis & $8,15,22,29$ \\
\hline L-Asparaginasa (IM) & $5000 \mathrm{UI} / \mathrm{m}^{2} /$ dosis & $12,15,18,1,24,27,30,33$ \\
\hline Metotrexato (IT) & $12 \mathrm{mg} /$ dosis & $1,12,33$ \\
\hline \multicolumn{3}{|l|}{ Inducción (Fase B) } \\
\hline Ciclofosfamida (IV) & $1000 \mathrm{mg} / \mathrm{m}^{2} /$ dosis & 36,64 \\
\hline Citarabina (IV) & $75 \mathrm{mg} / \mathrm{m}^{2} / \mathrm{dosis}$ & $38-41,45-48,52-55,59-62$ \\
\hline 6-Mercaptopurina (VO) & $60 \mathrm{mg} / \mathrm{m}^{2} /$ día & $36-63$ \\
\hline Metotrexato (IT) & $12 \mathrm{mg} /$ dosis & 45,59 \\
\hline \multicolumn{3}{|l|}{ Consolidación } \\
\hline 6-Mercaptopurina (VO) & $25 \mathrm{mg} / \mathrm{m}^{2} / \mathrm{dí} a$ & $1-56$ \\
\hline Metotrexato (IV en 24 horas) ${ }^{\ddagger}$ & $5000 \mathrm{mg} / \mathrm{m}^{2} /$ dosis & $8,22,36,50$ \\
\hline Metotrexato (IT) & $12 \mathrm{mg} /$ dosis & $8,22,36,50$ \\
\hline \multicolumn{3}{|l|}{ Reinducción (Fase A) } \\
\hline Dexametaxona (VO) & $6 \mathrm{mg} / \mathrm{m}^{2} / \mathrm{día}$ & $1-21$ \\
\hline Vincristina (IV) & $1,5 \mathrm{mg} / \mathrm{m}^{2} /$ dosis (Max. $2 \mathrm{mg}$ ) & $8,15,22,29$ \\
\hline Doxorrubicina (IV) & $30 \mathrm{mg} / \mathrm{m}^{2} /$ dosis & $8,15,22,29$ \\
\hline L-Asparaginasa (IM) & $10000 \mathrm{UI} / \mathrm{m}^{2} /$ dosis & $8,11,15,18$ \\
\hline \multicolumn{3}{|l|}{ Reinducción (Fase B) } \\
\hline Ciclofosfamida (IV) & $1000 \mathrm{mg} / \mathrm{m}^{2} /$ dosis & 36 \\
\hline Citarabina (IV) & $75 \mathrm{mg} / \mathrm{m}^{2} / \mathrm{dosis}$ & $38-41,45-48$ \\
\hline 6-Tioguanina (VO) & $60 \mathrm{mg} / \mathrm{m}^{2} /$ día & $36-49$ \\
\hline Metotrexato (IT) & $12 \mathrm{mg} /$ dosis & 45,59 \\
\hline \multicolumn{3}{|l|}{ Mantenimiento* } \\
\hline 6-Mercaptopurina (VO) & $50 \mathrm{mg} / \mathrm{m}^{2} / \mathrm{día}$ & Diariamente \\
\hline Metotrexato (IM) & $20 \mathrm{mg} / \mathrm{m}^{2} /$ dosis & Una vez a la semana \\
\hline
\end{tabular}

VO: Vía oral; IV: Vía intravenosa; IM: Vía intramuscular; IT: Vía intratecal; £: La respuesta al tratamiento se determina el día 8 y 33 de la fase de inducción para evaluar la respuesta pobre a la prednisona (contaje de blastos en sangre periférica $\geq 1000 / \mu \mathrm{L}$ ) y la remisión de la enfermedad ( $<5 \%$ de blastos en médula ósea regenerada, no evidencia de enfermedad extramedular, ausencia de blastos en sangre periférica y líquido cefalorraquídeo), respectivamente; $\ddagger$ : Posterior a 36 horas del inicio de las altas dosis de metotrexato, se requiere la administración de 12 dosis de leucovorina (dosis 1: $75 \mathrm{mg} / \mathrm{m} 2 / \mathrm{dosis}$ y dosis 2-12: $15 \mathrm{mg} / \mathrm{m} 2 /$ dosis, con un intervalo de 6 horas); *: Duración de 104 semanas desde el inicio del tratamiento. El riesgo fue definido como: a) Estándar: Sin criterios de alto riesgo y edad entre 1 a $<6$ años y leucocitosis al diagnóstico $<20000 / \mu \mathrm{L}$ y no estirpe $\mathrm{T} ; \mathrm{b}$ ) Intermedio: Sin criterios de alto riesgo y edad entre $<1$ o $>6$ años y/o leucocitosis al diagnóstico $\geq 20000 / \mu \mathrm{L}$ y/o estirpe T; c) Alto: Respuesta pobre a la prednisona y/o no remisión el día 33 de la fase de inducción y/o reordenamientos del gen MLL o gen de fusión BCR/ABL; el estatus del SNC no es un criterio para estratificación. En los casos de SNC3, se administrará (IT) metotrexato (12 $\mathrm{mg} /$ dosis), citarabina ( $40 \mathrm{mg} /$ dosis) e hidrocortisona ( $15 \mathrm{mg} /$ dosis) dos veces por semana hasta documentarse dos controles sucesivos sin células en el líquido cefalorraquídeo y luego se dará continuidad a la terapia intratecal especificada en las diferentes fases del protocolo.

manifestaciones cutáneas similares como las producidas por Leishmania (leishmaniasis cutánea), Mycobacterium (tuberculosis cutánea y lepra) y Treponema pallidum (goma sifilítica ulcerada) que son de gran carga en Venezuela. Debido a ello, es necesario incluir a estas enfermedades infecciosas dentro del diagnóstico diferencial de la NBCDP, principalmente en los países latinoamericanos.

Aunque las características clínicas y microscópicas pueden orientar el diagnóstico, la utilización de anticuerpos monoclonales que detecten a los antígenos asociados a CDp (CD123, TCL-1, CD2AP o CD303/BDCA2) es fundamental ${ }^{(13)}$. Se ha descrito el reporte de un caso erróneamente diagnosticado como cáncer de mama que posterior a ampliar el panel de anticuerpos se estableció el diagnóstico de NBCDP ${ }^{(12)}$. También existen resultados discordantes al analizar una muestra de piel y médula ósea ${ }^{(6)}$, apoyando los hallazgos del examen físico el diagnóstico de NBCDP.

El inmunofenotipo característico de las células neoplásicas contempla la coexpresión de CD4, CD56 y al menos un antígeno de $\mathrm{CDp}{ }^{(13)}$. El perfil de expresión de este y otros casos reveló que todos fueron CD4+/CD56+/CD123+, presentando dos sujetos expresión simultánea de TLC-1.

Respecto al pronóstico, se ha descrito un curso clínico muy agresivo con una tasa de mortalidad de $79 \%^{(1,4)}$. Sin embargo, en nuestro reporte destaca un paciente con un ECOG (escala de la Eastern Cooperative Oncology Group), nivel uno cuyo valor permaneció estable sin tratamiento 
durante aproximadamente 29 meses; dicha situación contrasta con la media de sobrevida global (SG) reportada en individuos que recibieron tratamiento $(8,7 \text { meses })^{(4)}$.

En relación al tratamiento, hasta el momento no se ha establecido un esquema estándar y la mayoría reciben esquemas empleados para linfoma, LLAy LMAcon resultados variables. En este sentido, se ha determinado remisión posterior a la fase de inducción en $67 \%$ y $27 \%$ de los pacientes que recibieron tratamiento para LLA/linfoma y LMA con una SG de 12,3 meses y 7,1 meses, correspondientemente ${ }^{(4)}$.

Se ha demostrado una mejora importante de la sobrevida cuando los pacientes son consolidados con trasplante de células madres hematopoyéticas (TCMH), los que recibieron $\mathrm{TCMH}$ alogénico presentaron una sobrevida libre de progresión (SLP) de 65\% el primer año y 55\% a los 3 años, mientras que la SG a 1 y 3 años de seguimiento fue de $68 \%$ y $58 \%$, respectivamente ${ }^{(14)}$. Los resultados de la SLP y SG en pacientes que recibieron $\mathrm{TCMH}$ autólogo fue significativamente inferior, $11 \%$ durante un año de seguimiento ${ }^{(14)}$. Por tales motivos, la consolidación mediante alotrasplante mieloablátivo es considerado el estándar de oro en la NBCDP; no obstante, debido a que la mayoría de los pacientes no son candidatos a este, por ser adultos mayores y/o frágiles, es razonable considerar el alotrasplante de intensidad reducida o el trasplante autólogo.

Información básica de la enfermedad ha demostrado una alta expresión de CD123 (receptor de IL-3) constituyendo una diana terapéutica importante. Por ello, se encuentra en ejecución un estudio clínico (NCT02113982) con el objetivo de evaluar el beneficio del tagraxofusp-erzs (Tagrax), una proteína que incluye componentes de la toxina diftérica fusionada a la IL-3 ${ }^{(15)}$. Se ha determinado una respuesta completa (CR) y respuesta clínica completa (CRc) en el $53,8 \%$ de pacientes de novo $(n=13)$ durante $3,9-12,2$ meses; por otro lado, en pacientes con enfermedad refractaria/recaída $(n=15)$ se documentó $C R$ en un paciente durante 111 días y CRc de 424 días en otro paciente. Por ello, la FDA aprobó en 2018 el uso de Tagrax como primera y segunda línea de tratamiento en pacientes mayores de dos años con NBCDP ${ }^{(16) .}$

Aunque la incorporación del Tagrax a los protocolos pudiera mejorar la sobrevida, principalmente en los no candidatos a trasplante, en nuestro medio existen recursos limitados lo cual puede afectar su incorporación, por ello los esquemas para LLA y linfoma son altamente recomendables.

Finalmente, es importante resaltar que este constituye el primer caso descrito en el HUC y la revisión revela poca experiencia en Venezuela ${ }^{(7)}$, donde destaca la dificultad diagnóstica y terapéutica. Por tales motivos, existe la necesidad de reportar casos similares para disponer de información que permita el diseño de esquemas que se adecuen a las características locales.

Agradecimientos: A la Lic. Travieso de la Unidad de Citometría de Flujo (Hospital de Clínicas Caracas).

Contribuciones de autoria: CFA, ZC, MAS, MS, HH han participado en concepción y diseño del artículo, recolección y obtención de los datos, redacción y revisión crítica del artículo y aprobaron la versión final.

Fuentes de financiamiento: El presente trabajo ha sido autofinanciado.

Conflicto de interés: Los autores declaramos ausencia de cualquier relación comercial y de financiamiento que pueda originar un posible conflicto de interés.

\section{REFERENCIAS BIBLIOGRÁFICAS}

1. Riaz W, Zhang L, Horna P, Sokol L. Blastic plasmacytoid dendritic cell neoplasm: update on molecular biology, diagnosis, and therapy. Cancer Control. 2014;21(4):279-289.

2. Khoury JD. Blastic plasmacytoid dendritic cell neoplasm. Curr Hematol Malig Rep. 2018;13(6):477-483.

3. Ceribelli M, Hou ZE, Kelly PN, Huang DW, Wright G, Ganapathi K, et al. A druggable TCF4- and BRD4-dependent transcriptional network sustains malignancy in blastic plasmacytoid dendritic cell neoplasm. Cancer Cell. 2016;30(5):764-778.

4. Pagano L, Valentini CG, Pulsoni A, Fisogni S, Carluccio P, Mannelli F, et al. Blastic plasmacytoid dendritic cell neoplasm with leukemic presentation: an Italian multicenter study. Haematologica. 2013;98(2):239-246
5. Möricke A, Reiter A, Zimmermann M, Gadner H, Stanulla M, Dördelmann $\mathrm{M}$, et al. Risk-adjusted therapy of acute lymphoblastic leukemia can decrease treatment burden and improve survival: treatment results of 2169 unselected pediatric and adolescent patients enrolled in the trial ALL-BFM 95. Blood. 2008;111(9):4477-89.

6. Lencastre A, Cabete J, João A, Farinha P, Ferreira G, Lestre S. Blastic plasmacytoid dendritic cell neoplasm. An Bras Dermatol. 2013;88(6 Suppl 1):158-61.

7. Rojas C, Jiménez L, Paz V, Vermiglio R, Acosta M, Chacín LF. Leucemia de células dendríticas. A propósito de un caso. Rev venez oncol. 2010;22(4).

8. Pennisi M, Cesana C, Cittone MG, Bandiera L, Scarpati B, Mancini V, et al. A case of blastic plasmocytoid dendritic cell neoplasm extensively studied by flow cytometryand immunohistochemistry. Case Rep Hematol. 2017;2017:4984951.

9. Chou PY, Lai CL, Huang P. Complete monocular vision loss due to optic nerve involvement of blastic plasmacytoid dendritic cell neoplasm. Acta Oncol. 2017:1-3.

10. Griffin JC, Aqel N, Siow W, Camilleri M, Ayto R. Blastic plasmacytoid dendritic cell neoplasm: a pathological illustration of two clinical cases. Ann Hematol. 2017;(10):1769-1770.

11. Deng W, Yang M, Kuang F, Liu Y, Zhang $\mathrm{H}$, Cao L, et al. Blastic plasmacytoid dendritic cell neoplasm in children: a review of two cases. Mol Clin Oncol. 2017;7(4):709-715.

12. Chen KC, Su TC, Chen DR, Liou JH. A case report: Blastic plasmacytoid dendritic cell neoplasm is misdiagnosed as breast infiltrating 
ductal carcinoma. Int J Surg Pathol. 2015;23(1):84-8.

13. Sullivan JM, Rizzieri DA. Treatment of blastic plasmacytoid dendritic cell neoplasm. Hematology Am Soc Hematol Educ Program. 2016;2016(1):16-23.

14. Kharfan-Dabaja M, Al MM, Deotare U, Raj RV, El-Jurdi N, Majhail N, et al. Haematopoietic cell transplantation for blastic plasmacytoid dendritic cell neoplasm: a North American multicentre collaborative study. $\mathrm{Br} \mathrm{J}$ Haematol. 2017;179(5):781

15. Kerr D 2nd, Zhang L, Sokol L. Blastic plasmacytoid dendritic cell neoplasm. Curr Treat Options Oncol. 2019;20(1):9.

16. Kinch MS, Griesenauer RH. 2018 in review: FDA approvals of new molecular entities. Drug Discov Today. 2019 May
31. pii: S1359-6446(19)30114-X. doi: 10.1016/j.drudis.2019.05.022.

Correspondencia: Carlos Flores-Angulo. Dirección: Ciudad Universitaria - Los Chaguaramos. Zona Postal 1040 Instituto Autónomo Hospital Universitario de Caracas. Distrito Capital - Venezuela. Teléfono: 58212-6067368.

Correo electrónico: carlos.jgfa@gmail.com

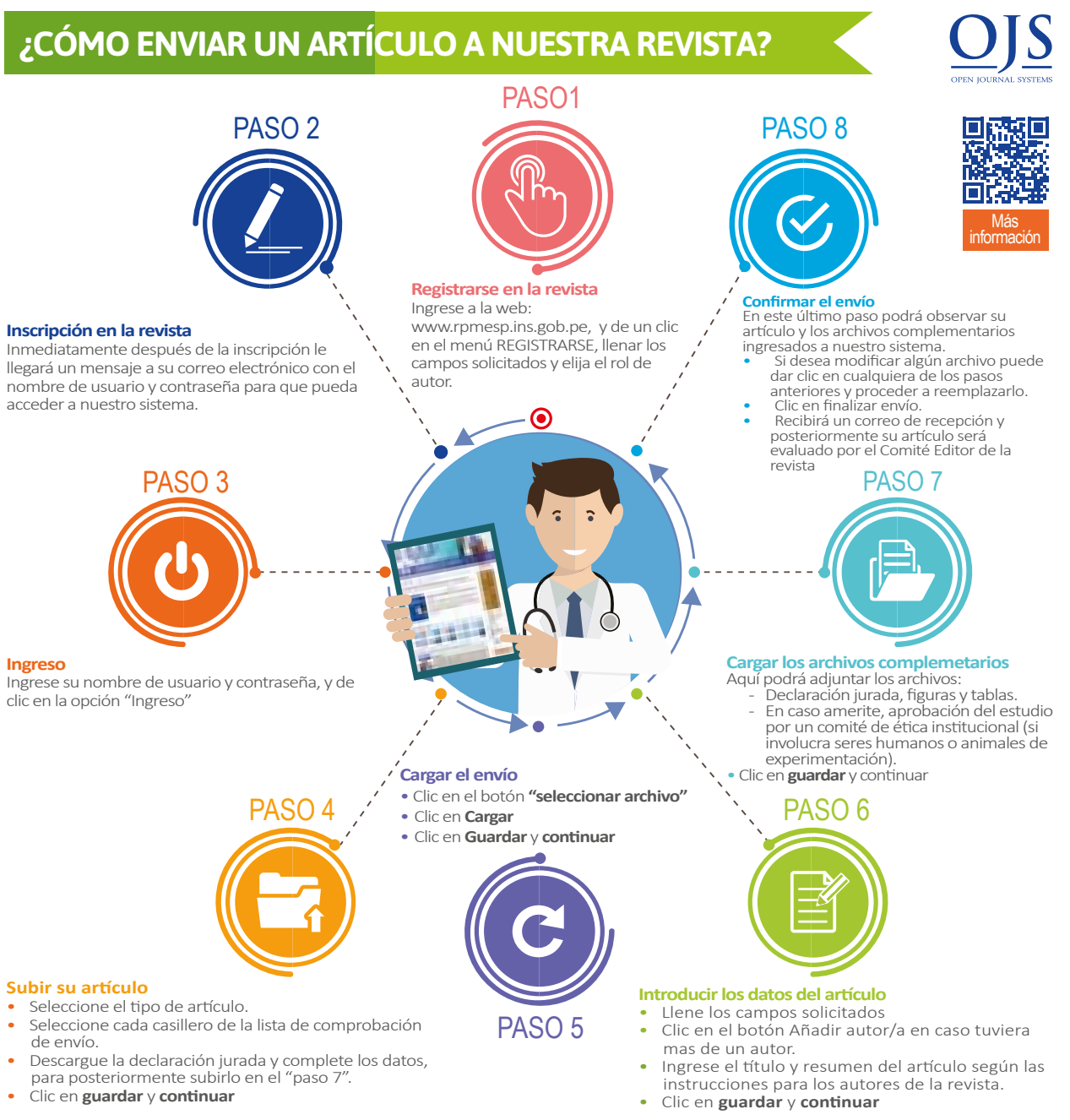

